Arteterapia. Papeles de arteterapia y educación para inclusión social ISSN-e 1988-8309

\title{
Congreso TRAUMA y ATTACHMENT
}

Roma, 22, 23 y 24 de septiembre de 2017

Marián López Fernández $\mathrm{Cao}^{1}$

Parte del equipo de investigación del proyecto "Aletheia: Artes, arteterapia, trauma y memoria emocional", tuvo la ocasión de asistir al congreso que sobre trauma y apego ha tenido lugar en Roma, auspiciado por la Asociación de Apego e la ISC.

A través de las distintas intervenciones, todas de carácter teórico, el trauma y las relaciones vinculares fueron abordadas desde diferentes perspectivas.

La Conferencia con Louis Cozolino, "Social brain and the impact of trauma", autor de la obra Neuropsicología del vínculo, constató cómo el vínculo es un elemento determinante en el análisis y restauración del trauma. En ella, el autor señaló cómo en la mente de los y las cuidadoras hay siempre un espacio para el ser al que se cuida y por ello, saber que se existe en la mente de alguien es un elemento esencial para la supervivencia y bienestar psicosocial. De forma contraria, no existir en la mente del otro crea un fuerte impacto emocional que está ligado con la experiencia traumática.

Seguidamente, el profesor Massimo Ammaniti centró su discurso sobre el vínculo madre/hijo, mostrando resultados de estudios realizados sobre una muestra de mujeres que habían sido madres y en las que el vínculo se desarrolla previamente en los meses de embarazo y se acentúa con la llegada del bebé, en el que se activa el circuito cerebral materno. A partir del nacimiento, la relación a través de gestos y miradas sincronizadas entre madre y bebé activan circuitos similares a los del enamoramiento. Asimismo, añadió que, a pesar de que la influencia de factores estresantes en la madre pueden dar como consecuencia mayor vulnerabilidad y dificultades de comportamiento en los bebés, un cuidado responsable y responsivo tiene enormes medidas reparadoras.

La conferenciante Diane Foscha, por su parte, insistió en la importancia de existir en la mente del otro, como base de la resiliencia y el apego seguro. Mostró varios casos desde la terapia AEDP, un tipo de terapia rápida basada en la trasformación a través de la creación de conexiones, el procesamiento de la rabia y la búsqueda de nuevos significados.

Por otro lado, la conferencia de Daniel Hugues, se centró en la terapia en diada con niños, acompañados de sus padres. En su intervención insistió en la necesidad de la co-regulación emocional y en la importancia de encontrarse en un lugar seguro

U niversidad Complutense de Madrid. 
para permitirse expresar sus emociones. Asimismo, insistió en la necesidad de dar sentido a estas emociones y en la importancia de los momentos de encuentro.

La conferencia de Stephen Suomi en la que expuso los resultados de las investigaciones llevadas a cabo en el centro de investigación de Washigton en la que observan las relaciones de los macacos y monos capuchino. Expuso las características de las relaciones vinculares y la organización social así como los comportamientos sociales complejos. Se centró en los juegos de imitación entre madres e hijos y también entre pares a partir de una cierta edad y la importancia de esos juegos en el establecimiento de vínculo y apego.

Daniel Siegel señaló los beneficios que se estaban observando desde la práctica del mindfulness, señalando cómo el ser visto, sostenido y seguro son los elementos básicos para mantener un apego seguro. Siegel recomienda la rueda de la conciencia (The wheel of Awareness) ${ }^{2}$ como método para la autorregulación emocional.

Una de las exposiciones más interesantes fue la conferencia de Bessel van der Kolk, donde reflexionó sobre la historia del tratamiento del trauma, desde Pierre Janet, pasando por su propia experiencia con los veteranos de la guerra del Vietnam. Se centró en la experiencia traumática relacionada específicamente con el trauma de desarrollo, aquel ocurrido y repetido durante la infancia. A través de su experiencia, basada en múltiples terapias combinadas (desde el yoga al neurofeedback), fue desgranando los posibles beneficios de éstas.

Finalmente, Pat Ogden, señaló como la terapia sensoriomotriz, siendo consciente de la postura corporal y su modo de relacionarse con el yo y el exterior, puede ayudar a mejorar a la persona. Asimismo, mostró como la terapia a través del tacto, tratada con suma delicadeza, puede ser una vía efectiva de elaboración del trauma.

\footnotetext{
Ver: https://www.youtube.com/watch?v=ODIFhOKahmk
} 